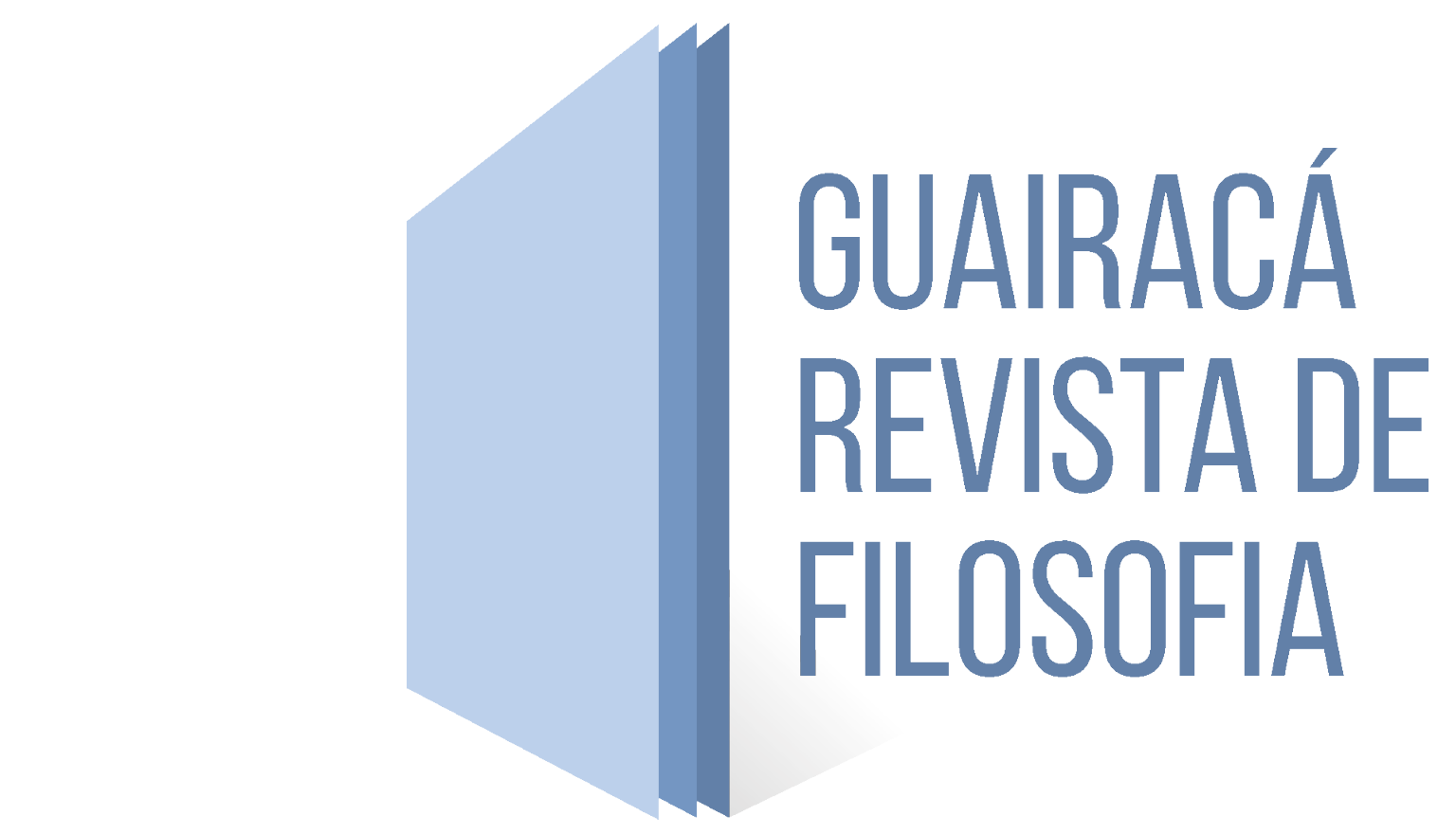

\title{
POR UMA DISTINÇ̃̃o ENTRE PENSAMENTOS RACIONAL E INTELECTUAL NO TRATADO V.3[49] DAS ENÉADAS DE PLOTINO ${ }^{1}$
}

Resumo: O objetivo desse estudo é argumentar que há uma diferença fundamental entre pensamentos racional e intelectual no contexto do tratado sobre a hipóstase cognitiva. Para obter êxito nessa empresa, dois expedientes teóricos serão utilizados: a discursividade e a não-discursividade com que se compreendem as respectivas formas de pensamento. Através dessas distinções, será possível especificar a singularidade do pensamento noético e, assim, desfazer mal-entendidos em relação à associação com o raciocínio vulgar.

Palavras-chave: Discursividade. Razão. Intelecto.

1. Esse trabalho é oriundo de uma seção da dissertação de mestrado.

2. Mestrando em Filosofia pela Universidade Federal do Ceará. Bolsista CAPES sob orientação do prof. Dr. José Carlos Silva de Almeida. E-mail:roberttxplus@gmail.com. 


\title{
FOR A DISTINCTION BETWEEN RATIONAL THOUGHT AND INTELLECTUAL THOUGHT IN THE V.3[49] TREATISE OF PLOTINUS ENNEADS.
}

\begin{abstract}
The aim of this study is to hold that there is a fundamental difference between rational thought and intellectual thought in the context of the treatise about the cognitive hypostasis. In order to achieve this goal, two theoretical expedients will be utilized: the discursiveness and the non-discursiveness with which are comprehended the respective forms of thinking. Through these distinctions it will be possible to specify the singularity of the noetic thought and, by doing so, to put light on the misunderstands related to the association with common reasoning.
\end{abstract}

Keywords: Discursiveness. Reason. Intellect.

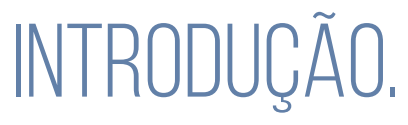

Parte significativa dos mal-entendidos em relação ao conceito plotiniano de pensamento noético, referente à segunda hipóstase, aquela na qual ser e pensar são o mesmo, deve-se a vinculação imediata que se faz entre esse tipo de pensamento e o nosso raciocínio vulgar. Assim, parece contra intuitivo admitir que todos os predicados atribuídos ao Nous possam ser de fato plausíveis, uma vez que destoam dos parâmetros comuns de razoabilidade. Tendo em vista essas nuances, o presente trabalho proporá analisar algumas passagens pertinentes do tratado V.3[49] ${ }^{3}$, tomando-o como espécie de estudo de caso para se apreender as aludidas distinções entre os pensamentos racional e intelectual. Por conseguinte, será possível argumentar em favor da singularidade do pensamento do Nous.

Em primeiro lugar, antes de assinalar como os recursos teóricos da discursividade e da não-discursividade são determinantes para se conceber o pensamento racional e o intelectual, é preciso seguir o itinerário reflexivo de Plotino. É interessante observar que ao longo do tratado ele procura realizar distinções entre o Uno, princípio não principiado que fundamenta e transcende o ser, o Intelecto e a Alma. Nesse contexto, Plotino faz um paralelo constante entre a Alma e o Intelecto objetivando indagar em qual instância conceitual se pode, de maneira mais adequada, caracterizar o autoconhecimento. Desta forma, a argumentação tem

3. A citação segue a ordem clássica, a qual descreve por meio da sucessão dos algarismos romanos e indo-arábicos, respectivamente o grupo de Enéadas (I a VI), a posição sistemática do tratado no grupo (1 a 9), a ordem cronológica (1 a 54), capítulo e intervalo entre linhas conforme edição grega. Vide: ROSSETI, 2006, p.177. 
como ponto de partida a questão do conhecimento ou, mais especificamente, do autoconhecimento. Em caráter propedêutico, Plotino estabelece em quais termos deve-se entender o conhecimento de si e a quem ele seria atribuível. No parágrafo inaugural ele acena o horizonte da pesquisa:

Deve ser diferenciado aquele que se pensa a si mesmo a fim de que ele possa, com um de seus constituintes, contemplar os outros, e assim se possa dizer que ele se pensa a si mesmo, na suposição de que o absolutamente simples não seria capaz de voltar-se sobre si e captar a si segundo o Intelecto? Ou é possível também para aquilo que não é composto ter uma percepção intelectual (noética) de si? (V.3[49] 1, $1-5)$.

\title{
A DEFINIÇÃO DO AUTOCONHECIMENTO: MARCO INICIAL PARA DISTINGUUR RAZÃO E INTELECTO4.
}

Nas primeiras linhas do texto, Plotino elenca um princípio que para ele é insofismável, qual seja: existe autoconhecimento verdadeiro. Negar a realidade desse axioma implica ter que aceitar toda sorte de absurdos, uma vez que, por definição, o Intelecto tem conhecimento de tudo que é inteligível. Logo, supor que o Intelecto tenha conhecimento de tudo sem que o tenha a respeito de si próprio não é razoável. Como poderia conhecer apenas os inteligíveis e não conhecer a si mesmo, sendo ele idêntico aos inteligíveis? Nesse plano argumentativo, Plotino pressupõe uma identidade que será constantemente reeditada ao longo do tratado, sob diferentes perspectivas e argumentos, a saber: o Intelecto é o seus pensamentos.

\begin{abstract}
não seria o todo [...] se aquele elemento que pensou os outros que estavam com ele não pensou também a si mesmo, e não seria aquilo que estamos procurando - uma coisa que pensa a si mesma - mas uma coisa pensando outra. Tem-se, então, que supor que algo simples pensa a si mesmo, e investigar tanto quanto possível, como faz isso, ou então abandonar a opinião de que algo realmente pense a si mesmo. Porém, abandonar essa opinião não é possível sem que muitos absurdos se sigam, pois mesmo que não atribuamos auto-intelecção à alma porque isto seria absurdo, ainda assim seria absolutamente absurdo não atribui-lo à natureza do Intelecto, e supor que ele tenha conhecimento de tudo o mais, mas não esteja num estado de conhecimento e compreensão de si mesmo? (V.3[49] 1, 10-19).
\end{abstract}

Ao deixar temporariamente em suspenso a questão concernente à natureza do autoconhecimento do Intelecto, Plotino lança uma indagação a ser examinada: sobre a alma, devemos dizer que ela tem conhecimento de si? Perguntemos mais: há algo nela que seja responsável por conhecer? Se sim, como isso ocorre? A

4. Em outro artigo, faço um breve comentário a respeito do tratado em estudo, detalhando os contornos do autoconhecimento. Aqui, faz-se apenas um resumo das linhas iniciais porque o propósito central não é o autoconhecimento, mas o paralelo entre o pensamento racional e o intelectual. Cf. SILVA,2018. 
resposta inicial que Plotino dá a essas perguntas constitui a definição elementar do conhecimento da alma e o cerne de todas as distinções posteriores: a relação de externalidade ou de internalidade no processo cognitivo. Ele considera que podemos dizer desde logo que o gênero de conhecimento proveniente da alma se refere apenas ao que é externo. Devido ao fato de que mesmo se houvesse um tipo de sensibilidade interna ao corpo, ainda assim o que é apreendido seria exterior a parte que percepciona. Tal formulação é fundamental para a conceituação do modo de conhecimento pertencente ao Intelecto, uma vez que será a internalidade dos inteligíveis o caminho adotado pelo tratado para articular a ontoepistemologia. Conforme ele discorre:

Acrescenta-se a essa parte perceptiva a observação de que ela apenas percebe, pois será a dimensão racional aquela responsável por julgar as imagens "mentais" que lhe foram apresentadas, isto é, advindas da sensibilidade. O modo como a razão o faz é através das operações dialéticas da combinação e da divisão. Essa mesma capacidade da alma de exercitar inteligência pela razão é a que possibilita a captação de reflexões do Intelecto, semelhante ao processo de compreensão decorrente da reminiscência platônica. É através da combinação das imagens provenientes da percepção e dos conceitos ou categorias do Intelecto que podemos passar das meras percepções para um conhecimento estruturado. Conforme explica o segundo capítulo:

[...] a faculdade da razão na alma faz seu julgamento, derivado das imagens mentais apresentadas a ela, que vêm da sensibilidade, combinando-as e dividindo-as; e, quanto às coisas que vêm a ela do Intelecto, ela observa o que se pode chamar de impressões, e tem, com respeito a elas, a mesma capacidade; e ela continua adquirindo compreensão ao reconhecer novas e recém chegadas impressões, unindo-as àquelas que estavam havia muito nela: esse processo é o que deveríamos chamar as reminiscências da alma (V.3[49] 2, 5-15).

Ainda imbuído de definir a alma e distingui-la do Intelecto, Plotino pergunta se o conhecimento que a alma tem por meio da sua parte pensante se esgota no que foi dito acima ou se ela se volta sobre si mesma tornando-se digna da atribuição do autoconhecimento, já que ela pensa e certamente participa, ao menos em certo nível, da intelecção sustentada pela hipóstase Nous. Se for esse o caso, isto é, se a alma tiver autoconhecimento, em que ela se diferenciaria do Intelecto?

Se concedermos autoconhecimento a essa parte da alma - pois temos que admitir que se trata de um Intelecto - temos também que perguntar como ela difere do Intelecto superior; mas, se não o concedermos (ao intelecto na alma) devemos ir àquele (o Intelecto superior) enquanto avançamos em nosso argumento e devemos considerar o que é "o si mesmo conhecer a si mesmo". Se o concedermos também aqui, no intelecto da alma, devemos investigar qual é a diferença no autopensamento (entre o intelecto da alma e o intelecto superior), pois, se não houver nenhuma, essa parte da alma já será puro Intelecto. Então, essa parte racional da alma, ela também se volta sobre si mesma? Não, ela tem compreensão das impressões que recebe de ambos os lados. Temos, então, que perguntar primeiro como ela tem compreensão (V.3[49] 2,15-25). 
Tendo como mote as preocupações ontoepistemológicas, o pensamento que Plotino está em busca deve ser verdadeiro, infalível e, portando, indissociável da realidade daquilo que é. Ele indica, por meio do curso do texto, que há dois parâmetros teóricos a serem levados em consideração: a internalidade ou externalidade com que se constitui o ato cognitivo. De antemão, é necessário definir que o conhecimento verdadeiro tem que ser interno a si mesmo, pois o que tem origem no exterior está relacionado às imagens ou representações (eidola) e não às ideias propriamente ditas. Logo, se o propósito é fugir de um modelo de metafísica que conteste a confiabilidade do conhecimento, não se pode admitir uma espécie de pensamento que dependa de dados exteriores.

O argumento, então, demonstrou que autopensamento no sentido primário e
próprio é algo que existe. Pensar (noeîn) é diferente quando está na alma, mas é
mais propriamente pensar no Intelecto (noûs). Pois a alma pensa a si mesma como
derivada de outro, mas o Intelecto pensa a si mesmo como aquilo que é e tal qual é,
a partir de sua própria natureza, ao voltar-se sobre si mesmo. Pois ao ver os entes, vê
a si mesmo, e ao ver está em ato, e este ato é ele mesmo. Pois, Intelecto e intelecção
são apenas um e ele se pensa como um todo com o todo de si, não pensa uma parte
de si com outra. Nosso argumento terá então demonstrado algo que tem força
persuasiva? Não, ele tem necessidade, não tem força persuasiva, pois a necessidade
está no Intelecto e a persuasão na alma (V.3 [49] 6, 1-10).

No trecho acima, Plotino diz que a alma pensa a si mesma como derivada de outro, enquanto o Intelecto pensa a si mesmo como ele é de fato, pois vê a si mesmo, isto é, se debruça sobre o que lhe é interior. Nesse passo, percebe-se claramente a vinculação entre internalidade, verdade e infalibilidade. Por conseguinte, fica definido que o autoconhecimento em sentido estrito pertence ao Intelecto e não à Alma, uma vez que apenas o Intelecto preenche as exigências teóricas do autoconhecimento. Entretanto, ainda é necessário esmiuçar como essas diferenças se dão e quais implicações decorrem delas no tocante a distinção do pensamento racional do pensamento intelectual.

\section{O MAL-ENTENDIDO DEVIDO À CONFUSÃO ENTRE PENSAMENTO RACIONAL E INTELECTUAL: COMO A DISCURSIVIDADE E A NÃO-DISCURSIVIDADE AUXILIAM NA COMPREENSÃO.}

O pensamento que o homem tem de si possui caráter existencial, está relacionado à percepção do que modernamente se entende como "eu", a saber, a instância que governa a consciência de uma identidade do tipo "eu sou o que sou" ou 
"tenho experiências de tais tipos". O Nous, enquanto totalidade do amálgama entre o que é e o que pode ser conhecido, quando se volta sobre si mesmo contempla tudo aquilo que é. Nosso conhecimento, inversamente ao do Intelecto, está associado à falta, o que nos motiva a buscar acréscimo epistêmico. Para além dessa diferença fundamental entre o nosso raciocínio e o pensamento intelectual, recomenda-se levar em conta que o homem é mistura de razão e sensopercepção, o que não permite a ele se fixar unicamente no pensamento. Esses são alguns motivos pelos quais se torna difícil entender o pensamento intelectual à luz do pensamento racional.

Para ilustrar como que pode causar embaraço a vinculação imediata do raciocínio vulgar com o pensamento do Nous, conforme definido por Plotino, vejase a crítica de Menn. Ele pratica até mesmo uma reductio ad absurdum ao considerar que a ideia plotiniana, segundo a qual o conhecedor, o conhecimento e o que é conhecido se identificam, expressa o mesmo que dizer que alguém por conhecer algo, torna-se aquela coisa que conhece. Em seguida, ele concede o beneplácito da dúvida ao cogitar a possibilidade desse tipo de conhecimento ser enunciado dessa maneira por se referir a outra espécie de conhecimento diferente da usual. Contudo, incorre na mesma dificuldade porque associa o conhecimento da hipóstase Nous ao conhecimento dianoético que a faculdade da razão humana possui. Leia-se o seguinte trecho:

A insistência de Plotino de que o conhecimento é idêntico com os seus objetos tem sido um grande obstáculo para levá-lo a sério enquanto um filósofo: pois, como se verá adiante, até mesmo neoplatonistas como Proclo ou rejeitam ou minimizam essa parte de seu pensamento. Plotino diz em V.9.7 que todo é́tı $\sigma \tau \eta \mu \alpha \mathrm{L}$, na medida em que são érı Tal coisa é, por si própria, absurda: quando eu conheço uma árvore, eu me torno idêntico com aquela árvore? Tentando interpretar caridosamente, nós teríamos que supor que Plotino está pensando não em um conhecimento ordinário, mas em um estado cognitivo especial no qual eu me identifico de alguma maneira com as coisas que eu conheço. Mas isso não é uma solução. Se levássemos a sério, isso implicaria na conclusão absurda de que (desde que as Formas platônicas são $\varepsilon \pi t \sigma \tau \eta \tau$ '́) eu mesmo deveria ser cada uma das Formas (tal soa como uma solução apenas porque estamos tentados a trapacear através do enfraquecimento do sentido de "identificar"). De que outra maneira nós poderíamos dar sentido ao que Plotino está dizendo? (MENN,2001,p.233, tradução nossa. $)^{5}$

5. "Plotinus's insistence that knowledge is identical with its object has been a major obstacle to taking him seriously as a philosopher: as we will see, even later neo-Platonists such as Proclus either reject or minimize this part of Plotinus's thought. Plotinus says in V.9 7 that all $\varepsilon \pi \iota \sigma \tau \eta \mu \alpha \iota$ 'inasmuch as

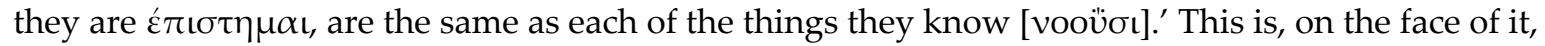
absurd: when I know a tree, do I become identical with that tree? Trying to interpret charitably, we might suppose that Plotinus is thinking, not of ordinary knowledge, but of a special cognitive state in which I am somehow identified with the things I know. But this is no solution: taken seriously, it would imply the absurd conclusion that (since the Platonic Forms are $\varepsilon \pi \iota \sigma \tau \eta \tau \alpha$ ) I must myself be each of the Forms (it only looks like there is a solution here because we are tempted to cheat by weakening the meaning of 'identify'). How else can we make sense of what Plotinus is saying?" 
Após supor que a atribuição de identidade à relação entre conhecedor e conhecido é absurda, Menn levanta a hipótese de que essas afirmações feitas por Plotino devem ser entendidas de forma alternativa. Para alcançar o objetivo pretendido, ele lança mão do que será o cerne de todo o seu itinerário investigativo, qual seja: o de que Plotino não está falando a respeito de um "sujeito" que conhece, mas da própria ciência da totalidade do que é. Ou seja, no campo cognitivo, o que é apreendido é o próprio conhecimento ou ciência a respeito daquilo que se conhece. Nos termos empregados pelo autor:

Um primeiro passo crucial, em direção a uma solução, é reconhecer que Plotino está afirmando não que o conhecedor é idêntico com o que é conhecido, mas que o conhecimento ou ciência é idêntico com o que é conhecido. A hipóstase vous, para Plotino, é uma ciência única de tudo o que pode ser compreendido, contendo as ciências particulares dentro de si; vous, e as ciências que ele contém, existe separadamente das almas (assim como as virtudes existem separadamente das almas para Platão ou para qualquer plantonista), e as almas tem conhecimento por participação no Nous ou nas ciências que ele contém (Idem, p.233-234, tradução nossa) ${ }^{6}$.

Tendo em vista o que preconiza a ontoepistemologia de Plotino, devo discordar de Menn, pois ele parece não dissociar a característica própria do pensamento do Nous, que é não-discursivo, não proposicional e não demonstrativo, do tipo de conhecimento que um homem particular tem, por intermédio da razão, sobre os dados senso perceptivos aos quais ele tem acesso. Nesse sentido, Menn opta por tentar salvar o constructo teórico de Plotino acrescentando premissas externas ao tratado propriamente dito. Ora, para Plotino, o Intelecto é o sujeito que pensa e os Inteligíveis são o conteúdo de seu pensamento. Embora exerçam papéis cognitivos distintos, ambos são idênticos, o que configura o autoconhecimento pleno. Menn, contudo, opta por abordar essa ideia de "sujeito" como ciência do que é conhecido, a fim de evitar mal-entendidos resultantes dessa formulação.

Conforme o que entende o presente estudo, é necessário fazer o esforço de articular os princípios de maneira harmônica, desde que eles não encerrem em contradição. O que não deve ser o caso, uma vez o fator cognitivo do pensamento intelectual não tem as mesmas peculiaridades do pensamento racional. Logo, o empreendimento de tornar absurdas as afirmações de Plotino sobre a relação

6. "A crucial first step toward a solution is to recognize that (in V.9 7 and elsewhere) Plotinus is asserting, not that the knower is identical with the thing known, but that the knowledge or science is identical with the thing known. The hypostasis vous, for Plotinus, is a single all-comprehending science, containing the particular sciences within itself; vous, and the sciences it contains, exist separately from souls (just as the virtues exist separately from souls for Plato or for any Platonist), and souls have knowledge by participating in vous or in the sciences it contains". 
sujeito-objeto carece de maior fundamentação no contexto das Enéadas ${ }^{7}$. A princípio, deve-se persistir no caminho de articulação entre essas teses antes de reduzi-las ao absurdo.

Mas, afinal, qual a natureza do pensamento do Intelecto quando se diz que nele há a base para a ontoepistemologia? No que a hipóstase, por assim dizer, difere do raciocínio humano vulgar? Nas linhas da abordagem plotiniana sobre os modos de conhecimento, pode-se constatar que fica patente a superioridade ontológica do conceito de Intelecto em relação aos outros, com a exceção do Uno que transcende ao pensamento que caracteriza o Nous. As ideias chave para aprofundarmos esse esclarecimento são as de pensamento discursivo e não-discursivo, as quais estão atreladas às ideias de proposicionalidade ou não-proposicionalidade. Por exemplo, a razão que se vale de raciocínios (dianoia) produz conteúdos em forma de proposições logicamente decompostas em sujeitos e predicados. Essa linguagem expressa a ideia de processo e de movimento, enquanto o pensamento noético é descrito como imediato, ou seja, sem mediações processuais pelas quais a proposição seria expressa. Por conseguinte, vê-se a relevância de considerar a distinção entre os planos da discursividade e não-discursividade. Conforme explica Reuter:

Sobre a caracterização dos dois tipos de pensamento, aquele que mais se aproxima do que consideramos pensamento [leia-se, o sentido comum que atribuímos à palavra] é uma atividade ou parte da alma (dianoia ou logismos), que envolve pensamento proposicional e discursivo. A discursividade é tanto temporal quanto lógica. Nós seguimos ideias logicamente das premissas à conclusão. Seguimos uma narrativa do começo ao fim. Mas, o que é então a atividade do Nous? É a ideia de um pensamento eterno coerente com a noção de Intelecto? A vida de um pensamento não discursivo é tida como um conceito que beira a contradição. Vamos começar pelo enigma levantado por Llyod. Ele inicia distinguindo dois tipos de pensamento não-discursivo. Um ele chama de pensamento imediato, como oposto à inferência e à demonstração - os problemas em torno dessa noção são os problemas do conhecimento intuitivo, por exemplo, o cogito cartesiano ou o reconhecimento das

\footnotetext{
7. É necessário esclarecer que por sujeito e objeto não se pretende equivaler o projeto de Plotino ao do edifício epistemológico moderno, mas tão somente assinalar que é necessário, para Plotino, haver o fator cognitivo responsável por conhecer e o fator cognitivo responsável por ser conhecido cf.Enéada VI. 7 [38].40.5-69. Além disso, há a motivação bibliográfica, pois os intérpretes consultados utilizam tais termos em inglês. Vide: MENN, 2001; REUTER, 1994.

8. On this characterization of the two species of thinking, the thinking that most closely corresponds with what we take to be thinking is an activity of psyche (or a part of psyche, the diánoia or logismós) is involved in propositional or discursive thought. This discursiveness is both temporal and logical [...]. We follow ideas (logically) from premises to conclusion. We follow a narrative (temporally) from beginning to end. But what then is the activity of Nous? Is eternal thought a coherent notion? [...] Nonpropositional thought or "non-discursive thinking" is taken to be a concept that comes dangerously close to contradiction [...] Let us begin by considering the enigma raised by Lloyd. He begins by distinguishing two types of non-discursive thought. One is what he calls "immediate thinking". It is opposed to inference and demonstration. The other (which he takes to be the more radical notion) he labels "non-propositional. It is associated with notions like "intuition" and "contemplation".
} 
premissas de um silogismo. O outro, que é mais radical, é o não-proposicional. Está associado à intuição e à contemplação. (REUTER, 1994, p.31-32, tradução nossa).

A passagem que arremata a tentativa de compreender a diferenciação entre a discursividade e a não-discursividade aparece no final do tratado quando Plotino explicita o caráter imediato do conhecimento inerente ao Intelecto, por contraste ao gênero da alma:

[...] o pensamento discursivo, a fim de expressar algo, tem de considerar uma coisa e outra. É assim que faz seu percurso. Mas, no que é absolutamente simples, que percurso é possível? Não, é suficiente apenas um toque do Intelecto, mas quando ele o toca, enquanto dura o contato, é absolutamente impossível falar e nem há tempo para tal. É somente depois que se consegue raciocinar (V.3 [49] 17, 25-30).

Se algo nos falta, temos que buscar o preenchimento dessa ausência. Uma vez que nos tornássemos plenos, não haveria necessidade de realizar esse percurso, utilizando a linguagem da passagem acima. O sujeito não possui os predicados, portanto, nesse caso, é necessário atribuir a ele as qualidades que o descreverão e que lhe darão sentido. Por conseguinte, a discursividade diz respeito ao raciocínio, o qual, influenciado pela composição com o corpo, não tem em si, pelo menos a princípio, com clareza a sua auto compreensão. Apenas depois de concluso o seu itinerário, poderá inferir que depende do Intelecto e que as regras de seu pensar derivam dele.

O princípio discursivo, como foi argumentado, impõe a introdução da proposicionalidade, o que indica que o conhecimento dependerá da transição de um estado ausente de conhecimento para outro após ter adquirido o conhecimento. A natureza do Intelecto pressupõe que fora dele não haja ser nem cognição. A nãodiscursividade abre espaço para a hipótese de uma diferenciação epistêmica que saía da ordem processual para a ordem intuitiva ou imediata. Ou seja, possibilita pensar a respeito de uma atividade cujo caráter seja puramente intelectual.

Através desses recursos teóricos é possível compreender em que sentido o pensamento noético preenche as exigências do autoconhecimento. Ora, enquanto na dianoia os fatores sujeito e objeto representam um conteúdo a ser apreendido, no nous, o conteúdo é intrínseco à atividade de sua própria essência. Tal ato, por sua vez, não marca uma dinâmica cronológica, mas uma dinâmica atemporal. O plano não-discursivo explica como é possível postular a relação daquele que pensa com o que é pensado para além do plano discursivo típico da faculdade da razão. Nesse sentido, a necessidade de que as Ideias sejam internas ao Intelecto é um princípio e a não-discursivdidade é o modo como se explica essa forma peculiar de pensamento. Se ainda restam dúvidas sobre esses recursos, é digna de nota a síntese apresentada 
por Gerson em seu famoso artigo a respeito de um tema que é um enigma da filosofia grega, a saber, a não-discursividade:

1)Esse tipo de pensamento não envolve nenhuma transição de um conceito para outro 2)Esse tipo de pensamento não envolve nenhuma distinção entre o lado de quem pensa e o lado do que é pensado 3) Esse tipo de pensamento envolve pensar tudo de uma vez (GERSON, 1970, p.263;267, tradução nossa) ${ }^{9}$.

A primeira e a terceira consideração estão em acordo com o que se desenvolve no presente trabalho. Entretanto, cabe fazer um contraponto à segunda afirmação. Nela Gerson atribui ao pensamento não discursivo a característica de que ele não admite distinções entre partes, as quais seriam responsáveis respectivamente por exercer o pensamento e por ser objeto dessa atividade de pensar. Para sustentar essa alegação, o autor discorre:

[...] o problema com a equação central, essa do pensamento e de seus objetos, é que ela não pode ser realmente compreendida, exceto como parte de uma teoria filosófica. A alternativa seria uma falsa história. Pois suponhamos que imaginemos uma cor azul e então imaginemos nós mesmos imaginando ou vendo uma cor azul: é de fato uma familiar e plausível alegação que nós não estamos aptos a distinguir as duas experiências. Isso tem sido claramente tomado para implicar que não há distinção entre nenhuma cor azul que estejamos conscientes e o assim chamado ato de estar consciente dele. Se isso é generalizado para cobrir dois tipos de consciência, uma chamada ver, ouvir e assim por diante, e outra chamada de pensamento a respeito de algo, nós temos um argumento para a identidade do pensamento e os seus objetos. Há uma óbvia objeção contra essa conclusão: ela faz desaparecer as qualidades quando não há quem tenha consciência delas (Idem, p.263-264, tradução nossa) ${ }^{10}$.

Conforme o entendimento desse estudo, Gerson comete alguns equívocos. Ele parece criticar o que seria a espécie de posição filosófica chamada de Idealismo, segundo a qual o sujeito ou a mente teria precedência em relação aos objetos, aos conteúdos ou à realidade. Entretanto, a busca de Plotino por identificar Intelecto e

9. "(1) This type of thinking involves no transition from concept to concept [...] (2) This type of thinking involves no distinction between the thinker or the thinking on one side and the object of his thinking or the thought on the other side [...] (3) This type of thinking involves thinking of everything at once."

10. "[...] the trouble with the central equation, that of thinking and its object, is that it cannot really be understood except as part of a philosophical theory. The alternative would be false history. For suppose we imagine a blue colour and then imagine ourselves imagining or seeing a blue colour: It is a familiar and indeed plausible claim that we are unable to distinguish the two experiences. This has of course been taken to imply that there is no distinction between any blue that we are aware of and the so called act of being aware of it. If this is generalized to cover two kinds of awareness, the one called seeing, hearing and so on, and the one called thinking of, we have an argument for the identity of thinking and its object. There is an obvious objection to the conclusion: it makes qualities disappear when no one is aware of them". 
Inteligíveis é justamente fundamentar a ontoepistemologia. Portanto, as qualidades que aparecem no domínio dos sensíveis, e que são reais para aquele que as percebe, não deixam de existir ontologicamente pela ausência hipotética de alguém que as perceba. O cosmos persiste a despeito de alguém que o conheça ou não, porque ele é efetivamente resultado da superabundância hipostática do Uno e do Intelecto.

Por outro lado, a razão só pode se dar conta desses dados porque no cosmos há uma ordem implicada pela inteligibilidade do Nous, a qual, por sua vez, rege a harmonia do universo. Assim, é legítimo concluir que o pensamento noético é simultâneo e inseparável do conteúdo de sua atividade de conhecer. Logo, não há margem para atribuir prioridade nem ao conteúdo nem àquele que o pensa. A razão humana, por seu turno, na medida em que não é causa de si mesma, mas provém de outro, não pode instituir nem destituir um ente de sua quididade.

No que diz respeito ao pensamento por excelência, ao ser descrito que sujeito e objeto implicam na inferência de um discurso de ordem proposicional, somente seria correto tecer afirmações dessa natureza se os Inteligíveis não fossem internos ou idênticos ao Intelecto. Nesse caso suposto, o Intelecto, realizando a função de pensar, faria a transição para alcançar o distante conhecimento que é seu objeto. Não funciona dessa maneira, tendo em vista que, se assim fosse, o Intelecto não poderia representar a esfera última do ser, pois algo escaparia a ele. O Intelecto, portanto, não pensa através de transições, mas pensa na ordem eterna os seus próprios pensamentos. Tal argumento, por conseguinte, visa sustentar que é possível distinguir partes, desde que elas não impliquem na instituição de duas essências. Por força desses argumentos, é coerente afirmar que sujeito e objeto, quando relacionados ao pensamento do Nous, não desembocam no discurso de ordem proposicional, uma vez que não há transição entre eles.

É significativo o fato de que Gerson elenque como objeção o argumento da "consciência", pois ele demonstra estar preocupado com a prioridade do sujeito em relação ao objeto. De maneira que a introdução desses termos iria resultar em um frágil idealismo. Todavia, essa dificuldade se aplicaria apenas ao pensamento discursivo. Como o artigo do próprio autor sugere, no pensamento não-discursivo não há transições, pois todo o conteúdo é imediato ao pensamento. Por conseguinte, é preciso ter em mente a simultaneidade lógica que envolve aquele que pensa, o pensar e o que é pensado. Logo, a não-discursividade explica como funciona o pensamento intelectual. A discursividade, por sua vez, está relacionada ao pensamento racional. No primeiro caso, o conteúdo do pensamento é interior e imediato. No segundo caso, o conhecimento é exterior e mediado pelas regras de raciocínio e pelas percepções advindas da sensibilidade. 


\section{CONCLUSÃO}

Pela análise dos textos e dos argumentos desenvolvidos, espera-se ter ficado claro que há uma distinção fundamental entre os pensamentos racional e intelectual para Plotino. O pensamento hipostático do Intelecto abrange o domínio que constitui a ontoepistemologia. Assim, define os paradigmas e princípios intelectivos a partir dos quais o pensamento humano é regrado. Devido às limitações de nossas faculdades cognitivas parece difícil compreender o Nous como possuindo as características de autoconhecimento pleno e pensamento puro, pois estamos sempre como partes indagando sobre o todo e porque sofremos afecções alheias à atividade do pensamento. Contudo, pelo menos internamente ao texto de Plotino, ao distinguirmos as respectivas formas de pensamento, torna-se coerente admitir que o Nous seja conceituado como essencialmente idêntico às Ideias e, portando, englobe o que é e o que é possível ser conhecido. Por fim, entende-se a distinção fundamental entre os pensamentos racional e intelectual, na medida em que eles operam respectivamente no plano discursivo e não-discursivo.

\section{REFERÊNCIAS BIBLIOGRÁFICAS}

GOLLNICK, Silvania. Ontologia e conhecimento no Tratado V.3(49) de Plotino. $128 \mathrm{f}$. Dissertação (Mestrado em Filosofia) - Universidade Federal de Santa Catarina, Florianópolis, 2005.

GERSON, Llyod. Non-Discursive Thought: An Enigma of Greek Philosophy. Proceedings of the Aristotelian Society, New Series, Vol. 70 (1969 - 1970), pp.261-274.

MENN, Stephen. Plotinus on the Identity of Knowledge with its Object. Apeiron. Volume 34, Issue 3, Pages 233-246. (2001).

REUTER, Mark. Plotinus on the role of Nous in Self-Knowledge. A thesis submitted for the degree of Doctor of Philosophy. Toronto: University of Toronto, 1994.

ROSSETTI, Livio. Introdução à Filosofia Antiga: Premissas filológicas e outras "ferramentas de trabalho". São Paulo: Paulus, 2006. 440p.

SILVA,R.B.B. Notas de leitura sobre o tratado V.3 (49) de Plotino: Conceituação da hipóstase Nous e delimitação da identidade entre intelecto e inteligíveis. Revista Seara Filosófica, Número 16, Inverno/2018, pp. 89-102. 